\title{
Profile of phenolic compounds and antimicrobial potential of hydroalcoholic extracts from cashew-apple coproducts
}

\author{
Amanda Germano Silveira1', Mônica Maria de Almeida Lopes², Elaine Cristina Pereira', \\ George Meredite Cunha de Castro², Thais Andrade Germano², Luciana de Siqueira Oliveira ${ }^{1 *}$, \\ Paulo Riceli Vasconcelos Ribeiro ${ }^{3}$, Kirley Marques Canuto ${ }^{3}$, Maria Raquel Alcântara de Miranda², \\ Joelia Marques de Carvalho ${ }^{4}$.
}

${ }^{1}$ Food Engineering Department, Federal University of Ceará, Campus do Pici, BI.858 CEP 60356-000, Fortaleza-CE, Brazil, ${ }^{2}$ Biochemistry and Molecular Biology Department, Federal University of Ceará, Campus do Pici, Bl. 907, CEP 60020-181, Fortaleza-CE, Brazil, ${ }^{3}$ Embrapa Agroindústria Tropical, Sara Mesquita 2270, CEP 60511-110, Fortaleza-CE, Brazil, ${ }^{4}$ Federal Institute of Education, Science and Technology of Ceará, Av. Treze de Maio, 2081, Benfica, CEP 60040-531, Fortaleza - CE, Brazil

\section{A B S TR A C T}

Phytochemicals from tropical fruits and their by-products have shown the potential to use as antimicrobial natural. This study aimed to optimize the recovery of phenolic compounds (total polyphenols and flavonoids) from cashew apple using ultrasound-assisted extraction to promote the functional attributes to its coproducts and to evaluate their antioxidant and antimicrobial potential. An experimental design applying a response surface methodology was used for the extraction process. The ethanol concentration (13.76 \% to $56.21 \%)$ and the ultrasonic bath time ( 21.71 to $78.28 \mathrm{~min}$.) were considered as independent variables, and the polyphenols content, total flavonoids as dependent variables. The phenolic profile of optimized hydroalcoholic extracts (UPLC-OToF-MSE) and their antimicrobial potential against

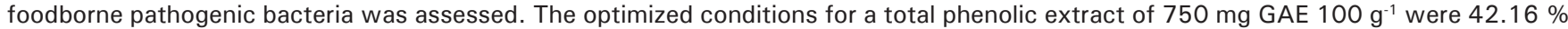
ethanol and $37.34 \mathrm{~min}$ in an ultrasonic bath, and for total flavonoids of $479.07 \mathrm{mg}$ of quercetin per $100 \mathrm{~g}^{-1}$ were $37.15 \%$ ethanol and $25.13 \mathrm{~min}$. A total of 15 compounds including quercetin and myricetin derivatives, gallic acid, and anacardic acid were identified. The extracts displayed effective action against Staphylococcus aureus and Listeria monocytogenes. The extracts were effective against foodborne pathogenic bacteria thus demonstrating their potential to be a good natural alternative to synthetic additives in the food industry.

Keywords: Coproducts fruit; Foodborne pathogenic bacteria; Response surface methodology; Ultrasound; UPLC-QToF-MSE

\section{INTRODUCTION}

Phenolic compounds, plant secondary metabolites, are important determinants in the sensory and nutritional quality of fruits and vegetables (Arruda et al. 2018) and which have shown a variety of activities, such as antioxidant, antimutagenic, antiallergenic, anti-inflammatory, and antimicrobial effects (Martins et al., 2011), can be used a lot in the areas of biology, medicine and food. According AyalaZavala et al. (2011), there is a potential to isolate specific phytochemicals from tropical fruits and their by-products to use as nutraceutical supplements, dietary additives, new food and pharmaceutical products thus contributing to the recovery of agroindustrial processing waste, with major industrial, economic and environmental impacts.
In the extraction of bioactive compounds, compared with conventional method, ultrasonic-assisted extraction (UAE) is one of the most inexpensive, rapid, simple and efficient techniques. UAE present high reproducibility, requires a short time for extraction, significant reduction in solvent consumption, significant reduction in solvent consumption and lower temperatures, consequently lower overall energy input (Yan et al. 2011, Chen et al., 2012, Fan et al., 2012). Due to these advantages, ultrasound technology is used in various industries, such as the food industry, chemical industry, and material industry (Leonelli and Mason, 2010).

In order, the optimization approaches based on an experimental design have been used to evaluate the variable affecting UAE (Ma et al., 2009). Response surface

\footnotetext{
*Corresponding author: Food Engineering Department, Federal University of Ceará, Campus do Pici, BI.858 CEP 60356-000,

Fortaleza-CE, Brazil. Phone: +55 85 3366-9753. E-mail: luciana.soy@gmail.com
} 
methodology (RSM), an effective statistical technique for the modeling and optimization of complex processes, has been used increasingly to optimize processing parameters and reduced number of experimental trials needed to evaluate multiple parameters and their interactions. Therefore, it is widely used to optimize the extraction parameters of compounds such as polysaccharides (Zhu and Liu, 2013), anthocyanins (Pinho et al., 2011), phenols (Wang et al., 2013), and proteins ( $\mathrm{Li}$ and $\mathrm{Fu}, 2005)$ from different materials.

Besides experimental design, some parameters such as solvent, temperature, pressure and time are the most common factors affecting compounds extraction (Hernandez et al., 2009). For the extraction of phenolic compounds from plant using UAE, the ethanol is recommended to be environmentally friendly and non-toxic food grade organic solvents for application in food systems (Chen et al., 2015). The recovery of phenolic compounds from acerola and lime waste by UAE was carried out using ethanol (46 and 55\%, respectively) as the solvent (Rezende et al., 2017; Rodsamran and Sothornvit, 2019).

The cashew apple (Anacardium occidentale L.) is known to has high amounts of ascorbic acid (Silva et al., 2013) and carotenoids besides phenolic compounds, such as phenolic acids, flavonoids and tannins (Michodjehoun-Mestres et al., 2009, Bataglion et al., 2015, Cunha et al., 2017). Despite being rich in nutrients just $10 \%$ of total cashew production is processed into juice, pulp, jam, alcoholic beverages, and confectionary (Assunção and Mercadante, 2003). Besides this, cashew is usually utilized as animal feed or discarded as waste due to highly perishable shelf-life that limits its alternative use for the food industry (Macedo et al., 2015). To add commercial value to the industrial waste from cashew processing, an effective bioactive compounds extraction would be beneficial to recover functional ingredients.

Therefore, the objective of this study was to use ultrasoundassisted extraction and to evaluate effect of extraction time and ethanol concentration as process variables to obtain bioactive compounds from cashew apple coproduct and in addition, from extraction optimized condition by RSM, analyze the antimicrobial potential of extract against food pathogenic bacteria.

In this point of view, the objective of this study was to optimize two parameters (time and ethanol concentration) for the highest phenolic and flavonoid extraction from cashew apple coproduct by UAE using RSM. In addition, antimicrobial potential against food pathogenic bacteria and phenolic profiling by UPLC-QTOF of extraction optimized condition were also evaluated.

\section{MATERIAL AND METHODS}

\section{Obtention of cashew apple coproduct}

Ripened cashew apples (peduncles with intense red color and dry nut) were sanitized with 200 ppm of commercial chlorine, and subsequent removal of nuts. The peduncles were processed in a domestic centrifuge $\left(V_{\text {icine }}{ }^{\circledR}\right.$, model VCC-8000) to separate the pulp from the fiber. Then, the bagasse was dried in a stove $\left(\right.$ Tecnal $^{\circledR}$, model TE-394/2) with forced air circulation until reaching $6.7 \%$ of humidity. The dried bagasse was then reduced to a thin power using a slicer (Marconi ${ }^{\circledR}$, model MA-48), and stored at $-20{ }^{\circ} \mathrm{C}$ until required for analyses.

\section{Ultrasound treatment to obtain the cashew apple coproduct extracts (CBE)}

Ultrasound-Assisted extraction (UAE) experiments were performed using an ultrasonic bath (Unique Model USC, 25 $\mathrm{kHz}, 150 \mathrm{~W}$ ) with a volume of $2.7 \mathrm{~L}$ (internal dimensions: $14 \times 24 \times 9 \mathrm{~cm})$. The extraction temperature was kept at 30 $\pm 1{ }^{\circ} \mathrm{C}$ by circulating water from a thermostatic water bath. Each extract was prepared in plastic tubes $(\mathrm{D}=30 \mathrm{~mm}$; $\mathrm{h}=115 \mathrm{~mm}$ ) using $1 \mathrm{~g}$ of the cashew apple coproduct powder and $10 \mathrm{~mL}$ of the ethanol solution $(1: 10, w / v)$. The ethanol concentration in water $(\%, v / v)$ and extraction time (min) varied according to the values given in Table 1. Then, extractive solution was centrifuged at $12.000 \mathrm{~g}$ at $4{ }^{\circ} \mathrm{C}$, and the supernatant was filtered in a Whatman N. 01 filter paper. The optimized extracts to phenolic (CBE-P) and flavonoid (CBE-F) contents, and others extracts were stored at $-20^{\circ} \mathrm{C}$ until required for analysis.

\section{Chromatographic profiling of extract}

The phenolic profile of CBE was conducted using an ultra-performance liquid chromatography (Acquity UPLC, Waters, UK) system coupled to a quadrupole/flight time mass spectrometer (Q-TOF MS, Waters, UK) (Sousa et al., 2016). Five $\mu \mathrm{L}$ of $\mathrm{CBE}$ were injected onto system. Chromatographic separation was achieved on an Acquity BEH C18 column $(150 \mathrm{~mm} \times 2.1 \mathrm{~mm}, 1.7 \mu \mathrm{m}$; Waters $)$ maintained at $40{ }^{\circ} \mathrm{C}$. The flow rate was $0.4 \mathrm{~mL} \mathrm{~min}^{-1}$, the injection volume was $5 \mu \mathrm{L}$ and the autosampler was set at $20{ }^{\circ} \mathrm{C}$. The mobile phase solutions consisted of $0.1 \%$ formic acid in water (A) and $0.1 \%$ formic acid in acetonitrile (B). The conditions of the linear gradient elution were optimized as follows: 2 to $95 \%$ B (0-15 min), 100\% B (15-17 min), $2 \%$ B (17.01), $2 \%$ B (17.02-19.01 min).

Later, the Q-TOF MS was used to detect phenolic profiling. The desolvation gas (high purity, $\mathrm{N}_{2}$ ) was adjusted to a temperature of $350{ }^{\circ} \mathrm{C}$ with a flow rate of $500 \mathrm{~L} \mathrm{~h}^{-1}$. The capillary and cone voltages were set at $2.6 \mathrm{kV}$ and $0.5 \mathrm{~V}$, respectively. The electrospray ionization source (ESI) operated in the negative ion mode ESI (-), which 


\begin{tabular}{|c|c|c|c|c|}
\hline \multirow[b]{2}{*}{ Runs } & \multicolumn{2}{|c|}{ Variables } & \multicolumn{2}{|c|}{ Responses } \\
\hline & Time $\left(X_{1}\right)(\min )$ & Ethanol $\left(\mathbf{X}_{2}\right)(\%)$ & $\begin{array}{c}\text { Total phenolics }\left(\mathrm{Y}_{1}\right)(\mathrm{mg} \text { acid } \\
\left.\text { gallic } 100 \mathrm{~g}^{-1}\right)\end{array}$ & $\begin{array}{l}\text { Total flavonoids }\left(\mathrm{Y}_{2}\right) \\
\left(\mathrm{mg} \text { quercetin } 100 \mathrm{~g}^{-1}\right)\end{array}$ \\
\hline 1 & $30.00(-1)$ & $20.00(-1)$ & 547.51 & 277.36 \\
\hline 2 & $30.00(-1)$ & $50.00(+1)$ & 756.54 & 408.88 \\
\hline 3 & $70.00(+1)$ & $20.00(-1)$ & 479.52 & 268.64 \\
\hline 4 & $70.00(+1)$ & $50.00(+1)$ & 810.46 & 448.85 \\
\hline 5 & $21.71(-1.41)$ & $35.00(0)$ & 762.80 & 467.65 \\
\hline 6 & $78.28(+1.41)$ & $35.00(0)$ & 860.73 & 600.41 \\
\hline 7 & $50.00(0)$ & $13.78(-1.41)$ & 536.26 & 199.31 \\
\hline 8 & $50.00(0)$ & $56.21(+1.41)$ & 682.05 & 283.16 \\
\hline 9 & $50.00(0)$ & $35.00(0)$ & 690.07 & 456.02 \\
\hline $10(C P)$ & $50.00(0)$ & $35.00(0)$ & 764.28 & 508.63 \\
\hline $11(C P)$ & $50.00(0)$ & $35.00(0)$ & 744.44 & 520.16 \\
\hline $12(\mathrm{CP})$ & $50.00(0)$ & $35.00(0)$ & 733.94 & 484.15 \\
\hline
\end{tabular}

(CP) Three central points of experimental design

is highly sensitivity to phenols. The mass accuracy and reproducibility were ensured by infusing lock mass calibration with leucine-enkephalin $\left(0.2 \mathrm{ng} \mu \mathrm{L}^{-1}[\mathrm{M}-\mathrm{H}]-\right.$ ion at $\mathrm{m} / \mathrm{z} 556.2771$ ) thorough lock spray at a flow rate of $20 \mu \mathrm{L} \mathrm{min}{ }^{-1}$. The mass spectrometry data were collected for $\mathrm{m} / \mathrm{z}$ values, which TOF mass range was from 110 to $1180 \mathrm{Da}$ with a scan time of 0.1 over an analysis time of $19 \mathrm{~min}$. The molecular formula assignments and accurate mass were obtained with the MassLynx 4.1 software (Waters, UK).

\section{Total phenolics}

The phenolic content was determined using Folin-Ciocalteu reagent as described by Obanda and Owuor (1997). The absorbance was measured at $700 \mathrm{~nm}$ in triplicate using a spectrophotometer (Kasuaki ${ }^{\circledR}$ UV/VIS, model IL-592-BI, Japan). Gallic acid was used as standard, and the results expressed as mg gallic acid $100 \mathrm{~g}^{-1}$ per dry weight (DW).

\section{Total flavonoids}

Total flavonoids content was determined using the method described by Patil et al. (2015) with some modifications. For the assay, $250 \mu \mathrm{L}$ of CBE-F was homogenized in $750 \mu \mathrm{L}$ of the extractive solution (isopropanol: acetic acid: water; $8: 1: 1 ; v / v / v)$. The absorbance was read at $370 \mathrm{~nm}$. Quercetin was used as standard. The assay was performed in triplicate and the data expressed as $\mathrm{mg}$ of quercetin $100 \mathrm{~g}^{-1} \mathrm{DW}$.

\section{Antimicrobial activity Bacterial strains}

The antimicrobial activity of CBE-P and CBE-F were evaluated against the Gram-positive bacteria Listeria monocytogenes ATCC 19115 (American Type Culture Collection) and Staphylococcus aureus ATCC 27664, and as well for the Gram-negative bacteria Escherichia coli ATCC 25922, Salmonella enteritidis IAL 1132 (Adolfo Lutz Institute) and Pseudomonas aeruginosa IAL 1026.

\section{Preparation and standardization of the inoculum}

The inoculum of the test bacteria was obtained by a culture growth method, standardized in preliminary tests, according to CLSI (2012) with modifications. Colonies were isolated from standard strains (Maintenance Agar, at $4{ }^{\circ} \mathrm{C}$ ) through of depletion streaks in Soy Trypticase Agar (TSA/OXOID ${ }^{\mathrm{TM}}$ ), except for Listeria monocytogenes that was enriched with $0.6 \%$ TSA of yeast extract (TSA-Ye/ $\left.\mathrm{BACTO}^{\mathrm{TM}}\right)$. The plates were incubated at $35^{\circ} \mathrm{C}$ for $24 \mathrm{~h}$. A colony isolated from each microorganism was selected and transferred in a tube containing $5 \mathrm{~mL}$ of the enrichment broth. The enrichment broths used were Soy Tripticase (TSB/DIFCO ${ }^{\mathrm{TM}}$ ) for L. monocytogenes and Escherichia coli and Brain Heart Infusion (BHI/BACTO ${ }^{\mathrm{TM}}$ ) for the other bacteria. The tubes were incubated under the same conditions $\left(35^{\circ} \mathrm{C}\right.$ for $\left.24 \mathrm{~h}\right)$. The inoculum concentration was adjusted by dilution with $0.1 \%$ peptone water, resulting in a microbial suspension of approximately $10^{8} \mathrm{CFU} \mathrm{mL} \mathrm{m}^{-1}$.

\section{Agar diffusion}

The antimicrobial activities of CBE-P and CBE-F were determined by agar diffusion, according to the methodologies described by CLSI (2012) and Oliveira et al. (2013), with modifications. Standardized bacterial suspensions were inoculated on sterile petri plates containing Müller-Hinton Agar (MH/OXOID ${ }^{\mathrm{TM}}$ ), except for the Listeria monocytogenes suspension, which used $\mathrm{MH}$ enriched with yeast $\left(\mathrm{MH}-\mathrm{YE}^{\mathrm{TM}}\right)$. After solidifying, $6 \mathrm{~mm}$ diameter orifices were made on the surface of the agar with a sterile punch. These orifices were filled with $25 \mu \mathrm{L}$ of the CBE-P and CBE-F. Afterwards, the plates were incubated at $35^{\circ} \mathrm{C}$ for $24 \mathrm{~h}$. After the incubation period, the diameters of the inhibition halos around the wells (including the well diameter) were measured using a calibrated scale. Halos with diameters greater than or equal to $9 \mathrm{~mm}$ were considered positive $(+)$, indicating bacterial sensitivity to the extracts (Oliveira et al., 2013). This method was conducted as a 
screening procedure for the antimicrobial activity of the extracts and was used as a basis for investigations using the broth microdilution method.

\section{Determination of the minimum inhibitory concentration (MIC) and minimum bacterial concentration (MBC) by the broth microdilution method}

The MIC and MBC of the extracts were determined using the broth microdilution method (Branen and Davidson, 2004, Brandt et al., 2010). The assays made against Staphylococcus aureus and Listeria monocytogenes were based on the screening results of the antibacterial activity. For the Staphylococcus aureus, the concentrations evaluated were: 50, 25, 12.5 and $6.25 \%(v: v)$ for both extracts (CBE-P and CBE-F), and for Listeria monocytogenes different concentrations were used: for polyphenols (CBE-P) $(50,25,12.5,6.25$ and $3.13 \%)$ and flavonoids (CBE-F) $(50,25,12.5$ and $6.25 \%)$. The optical density readings were made after the microplate preparation $(0 \mathrm{~h})$ and after an incubation period of $24 \mathrm{~h}$ and $35^{\circ} \mathrm{C}$, at $630 \mathrm{~nm}$ $\left(\mathrm{DO}_{630}\right)$ using a microplate reader (model ELx8081IU, Biotek Instruments, Inc., USA). The MIC was defined as the lowest antimicrobial concentration that completely inhibits the microbial growth (increase in the $\mathrm{DO}_{630} \leq 0.05$ after $24 \mathrm{~h}$ of incubation). To evaluate the bactericidal activity, $100 \mu \mathrm{L}$ of the suspensions that were classified as inhibitory, were spread on the surface of plates with TSA/ $\mathrm{OXOID}^{\mathrm{TM}}$ and TSA-Ye/BACTO ${ }^{\mathrm{TM}}$ respectively, for $S$. aureus and $L$. monocytogenes followed by incubation at $35{ }^{\circ} \mathrm{C}$ for $24 \mathrm{~h}$. The MBC was defined as the lowest antimicrobial concentration capable of reducing the number of viable cells by at least $3 \log _{10}$ CFU mL $\mathrm{mL}^{-1}(99.9 \%)$.

\section{Statistical analyses}

The effects of ultrasound processing were studied through a $2^{2}$ face-centered central composite rotatable design (CCRD) with three central points to evaluate the process repeatability, and two independent variables: ethanol concentration in water $(\%-v / v)$ and extraction time (min). The software Statistica $\left(\right.$ Statsoft ${ }^{\circledR}$ version 10) was used to generate the experimental planning and to handle the data. The generated three-factor central composite rotated design (CCRD) consisting of 12 runs ( 2 factorial points, 4 axial points and 3 central points) (Table 1). The results were analyzed by the response surface methodology (RSM), and the models were validated by ANOVA. The effects of the independent variables on the response were analyzed by Pareto charts. The surface graphs were used to evaluate the response changes (Table 1) as a function of the independent variables, thus finding the best operating conditions to evaluate the antioxidant and antimicrobial activities of the bagasse extracts.

\section{RESULTS AND DISCUSSION}

\section{Effect of ultrasound on the phenolics and flavonoids of bagasse cashew extracts: verification of the optimum conditions}

The cashew apple coproduct was sonicated according to the experimental planning presented in Tables 1 and 2. The models used in this work are represented by Equations (1) and (2).

$\mathrm{Y}_{1}=381.53-8.72 \mathrm{X}_{1}+0.059 \mathrm{X}_{1}{ }^{2}+25.23 \mathrm{X}_{2}-0.34 \mathrm{X}_{2}{ }^{2}$ $+0.101 \mathrm{X}_{1} \mathrm{X}_{2}$

$\mathrm{Y}_{2}=-290.46-2.97 \mathrm{X}_{1}+0.029 \mathrm{X}_{1}^{2}+43.44 \mathrm{X}_{2}-0.590 \mathrm{X}_{2}^{2}+0.041$ $\mathrm{X}_{1} \mathrm{X}_{2}$

Where $\mathrm{Y}_{1}$ : Total phenolics ( $\mathrm{mg}$ of acid gallic $100 \mathrm{~g}^{-1}$ ), $\mathrm{Y}_{2}$ : Total flavonoids (mg of quercetin $100 \mathrm{~g}^{-1}$ ), $\mathrm{X}_{1}$ : time (min) and $\mathrm{X}_{2}$ : ethanol $(\% ; v / v)$. The $\mathrm{R}^{2}$ of the models presented in Eqs. (1) and (2) were: 0.82 and 0.93 , respectively. The calculated F-value $\left(\mathrm{F}_{9.7}\right)$ were: 27.58 (Eq. (1)) and 70.36 (Eq. (2)).

(CP) Three central points of experimental design

The models were validated by ANOVA (Tables 2 and 3) analysis and the F-test at $95 \%$ confidence level before building the response surface graphs presented in Fig. 1. All models were statistically significant since the calculated $\mathrm{F}$ values were higher than the listed $\mathrm{F}$ value at $95 \%$ confidence level.

The linear effects of ethanol observed on the Pareto chart (Fig. 1A) for the total phenolics was positive and significant, meaning that an increase in the ethanol concentration favored the extraction of the phenolic compounds. Furthermore, the quadratic effect of ethanol was significant and negative meaning that an increase in ethanol (\%) favors the phenolics extraction (Figs. 1A; 1B). At high ethanol $(\%)$ values, the concentration of phenolics decreased. The time (linear or quadratic) did not influence the extraction conditions at $5 \%$ of significance, nor the interaction between time and ethanol concentration (Figs. 1A; 1B). The best conditions for the phenolics extraction were: ethanol $42.16 \%(v / v)$ and an extraction time of $37.34 \mathrm{~min}$, with predicted yield of $750.51 \mathrm{mg}$ of gallic acid per $100 \mathrm{~g}^{-1}$.

According to Fonteles et al. (2016) sonicated cashew apple bagasse showed higher antioxidant activity, higher total phenolic compounds and higher vitamin $\mathrm{C}$ content when compared to the non-sonicated samples. According to the authors, the increase in the antioxidant compounds is because the sonication induced the disruption of the cashew bagasse parenchyma, which resulted in 
Table 2: Analysis of variance for studied experimental response on phenolics content

\begin{tabular}{|c|c|c|c|c|c|c|c|c|}
\hline Source & $\begin{array}{c}\text { Sum of } \\
\text { Square (SS) }\end{array}$ & $\begin{array}{c}\text { Degree of } \\
\text { freedom }\left(D_{f}\right)\end{array}$ & $\begin{array}{c}\text { Mean } \\
\text { Squares (MS) }\end{array}$ & Source & SS & $D_{f}$ & MS & $F_{\text {(calculated value) }}$ \\
\hline $\mathrm{X}_{1}$ (time) (L) & 1935.80 & 1 & 1935.81 & Regression & 144729.11 & 11 & 126399 & 27.58 \\
\hline $\mathrm{X}_{1}^{2}($ Time $)(\mathbf{Q})$ & 3624.30 & 1 & 3624.29 & Error & 27494.40 & 6 & 4582.40 & \\
\hline $\mathrm{X}_{2}$ (ethanol) (L) & 69549.60 & 1 & 69549.57 & $\mathrm{R}^{2}$ & 0.93 & & & \\
\hline $\mathrm{X}_{2}^{2}$ (ethanol) (Q) & 38410.80 & 1 & 38408.94 & $\mathrm{~F}_{\text {(isted value) }}$ & 3.09 & & & \\
\hline$x_{1} x_{2}$ & 3716.10 & 1 & 3716.09 & & & & & \\
\hline Lack of fit & 24541.20 & 3 & 8180.39 & & & & & \\
\hline Pure Error & 2953.30 & 3 & 984.42 & & & & & \\
\hline Total SS & 144729.10 & 11 & 126399.50 & & & & & \\
\hline
\end{tabular}

Table 3: Analysis of variance for studied experimental response on phenolics content on flavonoids content

\begin{tabular}{|c|c|c|c|c|c|c|c|c|}
\hline Source & $\begin{array}{c}\text { Sum of } \\
\text { Square (SS) }\end{array}$ & $\begin{array}{c}\text { Degree of } \\
\text { freedom }\left(D_{f}\right)\end{array}$ & $\begin{array}{c}\text { Mean } \\
\text { Squares (MS) }\end{array}$ & Source & SS & $D_{f}$ & MS & $\mathbf{F}_{\text {(calculated value) }}$ \\
\hline $\mathrm{X}_{1}$ (time) (L) & 5996.30 & 1 & 5996.30 & Regression & 159497.60 & 11 & 150918.10 & 70.36 \\
\hline $\mathrm{X}_{1}^{2}($ Time $)(\mathrm{Q})$ & 877.90 & 1 & 877.90 & Error & 12869.3 & 6 & 2144.90 & \\
\hline $\mathrm{X}_{2}$ (ethanol) (L) & 23107.40 & 1 & 23107.40 & $\mathrm{R}^{2}$ & 0.82 & & & \\
\hline $\mathrm{X}_{2}^{2}$ (ethanol) $(\mathrm{Q})$ & 116054.30 & 1 & 116054.30 & $\mathrm{~F}_{\text {(listed value) }}$ & 3.09 & & & \\
\hline$x_{1} X_{2}$ & 592.50 & 1 & 592.50 & & & & & \\
\hline Lack of fit & 10443.20 & 3 & 3481.10 & & & & & \\
\hline Pure Error & 2426.10 & 3 & 808.70 & & & & & \\
\hline Total SS & 159497.60 & 11 & 150918.10 & & & & & \\
\hline
\end{tabular}

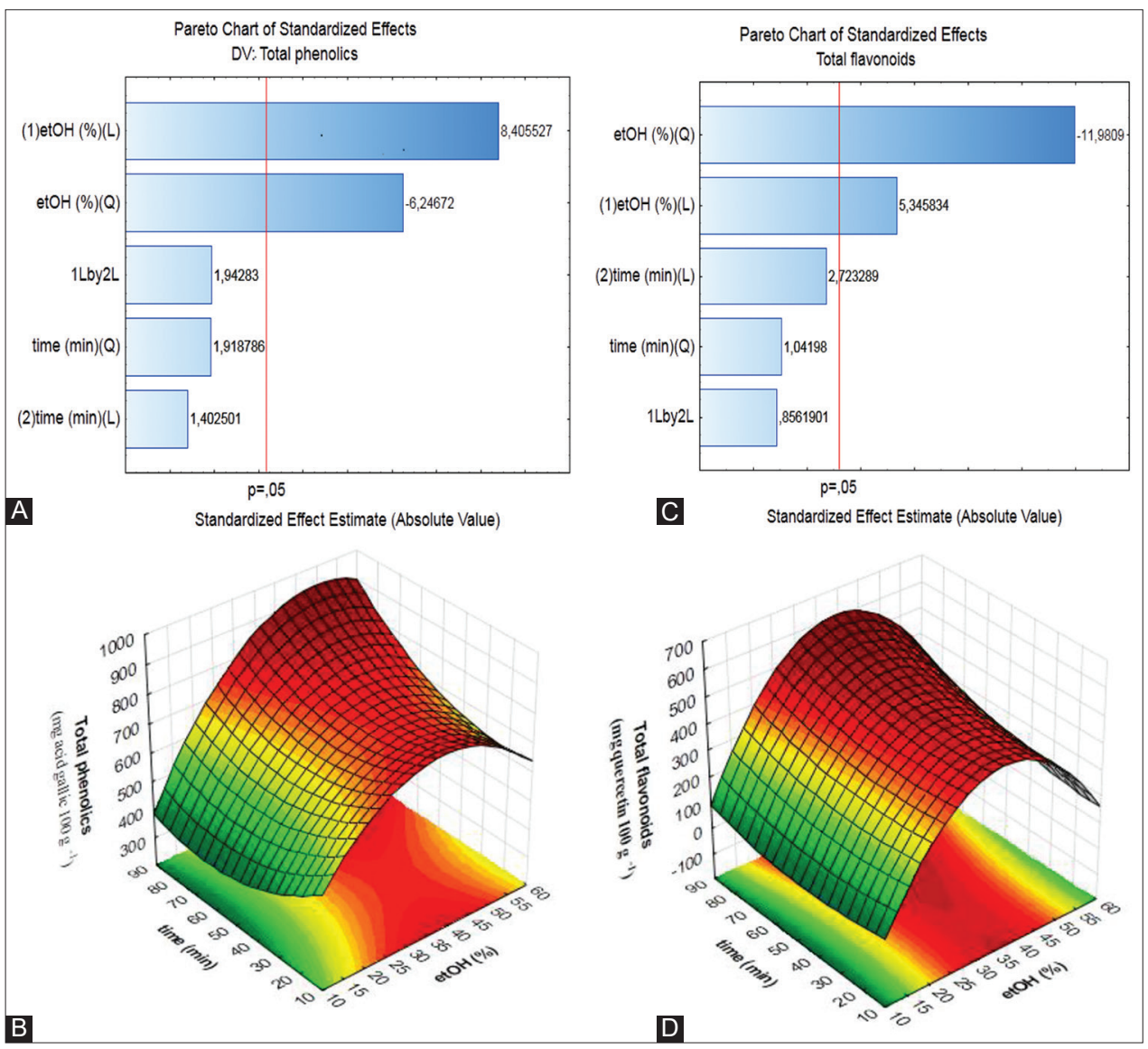

Fig 1. Pareto test and surface response graph for polyphenolic ( $A$ and $B)$ and flavonoid ( $C$ and $D)$ optimized extraction from cashew-apple coproduct.

lower resistance to water diffusion, less hysteresis, and an increased rehydration rate. Rodrigues et al. (2015) evaluated the effect of ultrasound extraction on phenolics and anthocyanins in jabuticaba peel, and these authors 
optimized the operating conditions of extraction to $10 \mathrm{~min}$ in a $46 \%(v / v)$ ethanol: water solution acidified at $\mathrm{pH} 1$, with a yield of phenolics compounds of $92.80 \mathrm{mg}$ of gallic acid per $\mathrm{g}^{-1}$ dry peel.

Interestingly, as reported by these authors, the mild concentration of ethanol (46\%) was observed as the optimized condition for extraction in our study for phenolics $(\sim 43 \%)$. The effect of the ultrasound is attributed to its interaction with the plant material, altering its physical and chemical properties, and to the cavitation effect, which facilitates the release of extractable compounds and enhances the mass transport by disrupting the plant cell walls (Chemat et al., 2011). Solvent concentration plays a significant role in the extraction of phenolic compounds from plant materials, and ethanol is the preferred solvent in the food industry as it is regarded as a dietary alcohol.

For total flavonoids, the quadratic effect of ethanol was significantly more negatively pronounced, meaning that the increase in ethanol (\%) favors the extraction of flavonoids only up to a certain value (Figs. 1C;1D). The linear effects of ethanol were positive and significant, meaning that the increase of ethanol concentration favored the extraction of the flavonoid compounds. However, at high ethanol (\%) values (up $50 \%$ ), the concentration of flavonoids decreased (Figs. 1C; 1D). The time (linear or quadratic) did not influence the extraction conditions at $5 \%$ of significance, nor the interaction between the independent variables (time versus ethanol) (Figs. 1C; 1D). The best conditions were: ethanol $37.15 \%(v / v)$ and an extraction time of $25.13 \mathrm{~min}$, with predicted yield of $479.07 \mathrm{mg}$ of quercetin $100 \mathrm{~g}^{-1}$.

To standardize the extraction of phytochemicals is important to maximize the yield, and ultrasound assisted extraction has shown reduced the extraction time significantly if compared to the traditional methods, besides to use less extraction solvent when conditions are optimized.

\section{Phenolic profile of cashew bagasse extract by UPLC- QTOF}

The chromatographic profile of the extract was able to identify 15 compounds through the observed retention times, fragmentation patterns $\left(\mathrm{MS}^{2}\right)$ and compared with data reported by other studies (Fig. 2).

UPLC-QTOF-MS chromatogram of the chemical constituents present in the hydroalcoholic extract of cashew-apple coproduct. Mode ESI-110-1180 Da. Waters Acquity UPLC BEH column (150 x $2.1 \mathrm{~mm}, 1.7 \mu \mathrm{m})$, fixed temperature $40{ }^{\circ} \mathrm{C}$, mobile phases water with $0.1 \%$ formic acid (A) and acetonitrile with $0.1 \%$ formic acid (B), gradient ranging from $2 \%$ to $95 \%$ B (15 min), flow rate $0.4 \mathrm{~mL} \mathrm{~min}^{-1}$ and injection volume $5 \mu \mathrm{L}$.

Table 4 shows the compounds tentatively identified. Peaks 2, 3 and 4 were identified as citric, gallic acids and dehydrophaseic acid hexoside by their ion $[\mathrm{M}-\mathrm{H}]$ at $\mathrm{m} / \mathrm{z}$ 191, 169 and 443, respectively. Their fragmentation patterns at $\mathrm{m} / \mathrm{z} 111,125$ and 281 are characteristic of the loss of water molecules, $\mathrm{CO}_{2}$ and hexose (Spínola

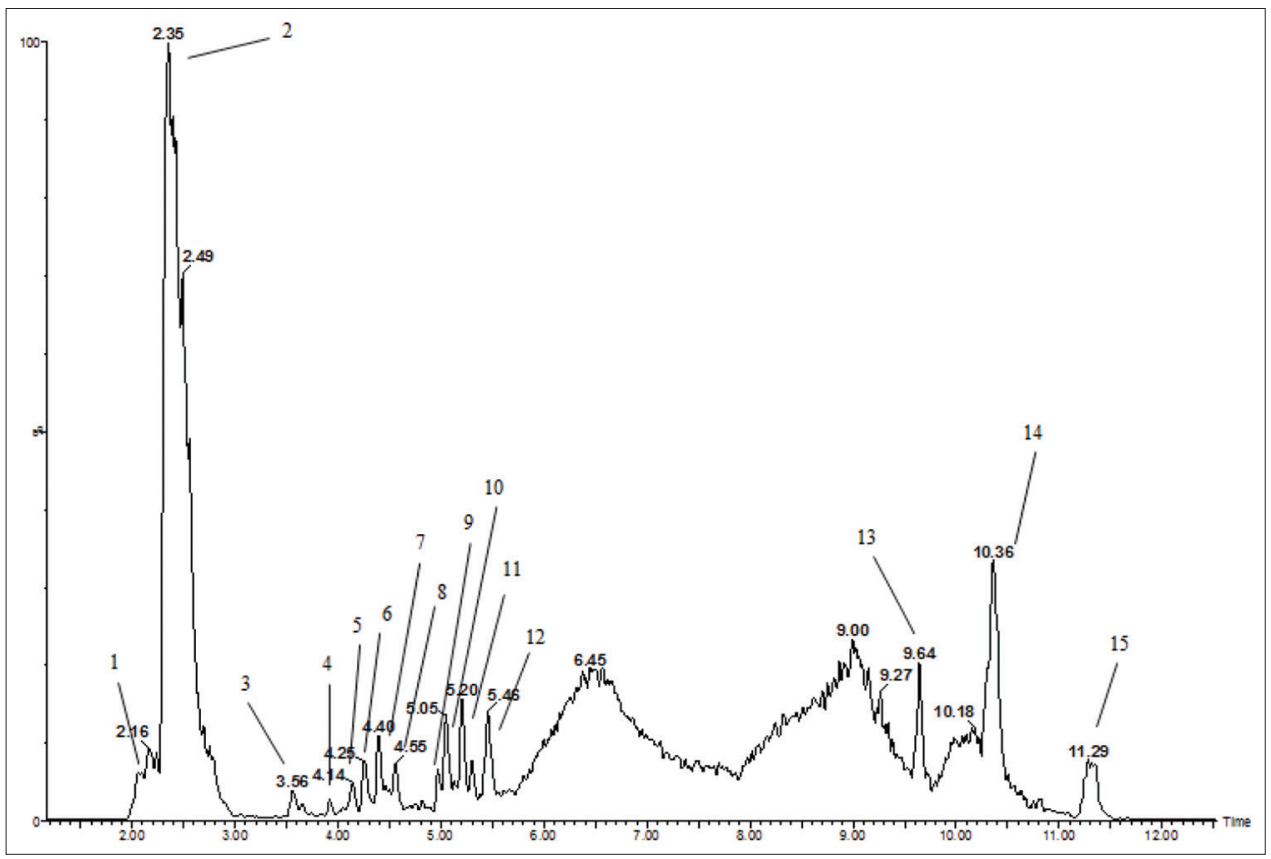

Fig 2. Chromatographic profile obtained from cashew-apple coproduct. 
Silveira, et al.

Table 4: Identification of compounds in cashew-apple coproduct by UPCL-QTOF-MSE

\begin{tabular}{|c|c|c|c|c|c|c|c|c|}
\hline $\begin{array}{l}\text { Peak } \\
\text { no. }\end{array}$ & $\begin{array}{l}\text { Rt } \\
\text { min }\end{array}$ & $\begin{array}{c}{[\mathrm{M}-\mathrm{H}]^{-}} \\
\text {Observed }\end{array}$ & $\begin{array}{c}{[\mathrm{M}-\mathrm{H}]^{-}} \\
\text {Calculated }\end{array}$ & $\begin{array}{l}\text { Product lons } \\
\text { (MS/MS) }\end{array}$ & $\begin{array}{l}\text { Empirical } \\
\text { Formula }\end{array}$ & $\begin{array}{l}\text { Ppm } \\
\text { (error) }\end{array}$ & Putative Name & Referências \\
\hline 1 & 2.36 & 195.0500 & 195.0505 & - & $\mathrm{C}_{6} \mathrm{H}_{11} \mathrm{O}_{7}$ & -2.6 & Unknow & - \\
\hline 2 & 1.87 & 191.0194 & 191.0192 & 111.0101 & $\mathrm{C}_{6} \mathrm{H}_{7} \mathrm{O}_{7}$ & 1.0 & Citric acid & (Spínola et al., 2015) \\
\hline 3 & 3.55 & 169.0138 & 169.0137 & 125.0204 & $\mathrm{C}_{7} \mathrm{H}_{5} \mathrm{O}_{5}$ & 0.6 & Galic acid & $\begin{array}{l}\text { (Michodjehoun-Mestres, } \\
\text { et al., 2009) }\end{array}$ \\
\hline 4 & 3.91 & 443.1906 & 443.1917 & $\begin{array}{l}281.1108 \\
143.0502 \\
119.0332\end{array}$ & $\mathrm{C}_{21} \mathrm{H}_{31} \mathrm{O}_{10}$ & -2.5 & $\begin{array}{l}\text { Dehydrophaseic acid } \\
\text { hexoside }\end{array}$ & (Cunha et al., 2017) \\
\hline 5 & 4.14 & 635.0871 & 635.0884 & $\begin{array}{l}465.0600 \\
313.0526\end{array}$ & $\mathrm{C}_{27} \mathrm{H}_{23} \mathrm{O}_{18}$ & -2.0 & Unknow & - \\
\hline 6 & 4.25 & 479.0820 & 479.0826 & $\begin{array}{l}317.0299 \\
316.0206\end{array}$ & $\mathrm{C}_{21} \mathrm{H}_{19} \mathrm{O}_{13}$ & -1.3 & Myricetin-O-hexoside & (Cunha et al., 2017) \\
\hline 7 & 4.39 & 463.0871 & 463.0877 & $\begin{array}{l}317.0223 \\
316.0215\end{array}$ & $\mathrm{C}_{21} \mathrm{H}_{19} \mathrm{O}_{12}$ & -0.6 & Myricetin-O-rhamnoside & (Cunha et al., 2017) \\
\hline 8 & 4.56 & 447.0909 & 447.0927 & $\begin{array}{l}301.0310 \\
300.0235\end{array}$ & $\mathrm{C}_{21} \mathrm{H}_{19} \mathrm{O}_{11}$ & -4.0 & Quercetin-O-rhamnoside & $\begin{array}{l}\text { (Michodjehoun-Mestres, } \\
\text { et al., 2009) }\end{array}$ \\
\hline 9 & 4.97 & 609.1248 & 609.1244 & $\begin{array}{l}317.0185 \\
316.0215\end{array}$ & $\mathrm{C}_{30} \mathrm{H}_{25} \mathrm{O}_{14}$ & 0.7 & Myricetin derivative & - \\
\hline 10 & 5.05 & 609.1242 & 609.1244 & $\begin{array}{l}317.0285 \\
316.0237\end{array}$ & $\mathrm{C}_{30} \mathrm{H}_{25} \mathrm{O}_{14}$ & -0.3 & Myricetin derivative & - \\
\hline 11 & 5.20 & 593.1293 & 593.1295 & $\begin{array}{l}301.0357 \\
300.0245\end{array}$ & $\mathrm{C}_{30} \mathrm{H}_{25} \mathrm{O}_{13}$ & -0.3 & Quercetin derivative & - \\
\hline 12 & 5.46 & 329.2322 & 329.2328 & $\begin{array}{c}229.1402, \\
211.1312 \\
171.1001\end{array}$ & $\mathrm{C}_{18} \mathrm{H}_{33} \mathrm{O}_{5}$ & -1.8 & $\begin{array}{l}\text { Trihydroxy-octadecenoic } \\
\text { acid }\end{array}$ & (Farag, et al., 2015) \\
\hline 13 & 9.64 & 341.2119 & 341.2117 & $\begin{array}{l}297.2242 \\
119.0493\end{array}$ & $\mathrm{C}_{22} \mathrm{H}_{29} \mathrm{O}_{3}$ & 0.6 & (15:3)-Anacardic acid & (Cunha et al., 2017) \\
\hline 14 & 10.37 & 343.2262 & 343.2273 & 299.2346 & $\mathrm{C}_{22} \mathrm{H}_{31} \mathrm{O}_{3}$ & -3.2 & (15:2)-Anacardic acid & (Cunha et al., 2017) \\
\hline 15 & 11.29 & 345.2419 & 345.2430 & 301.2546 & $\mathrm{C}_{22} \mathrm{H}_{31} \mathrm{O}_{3}$ & -3.2 & (15:1)-Anacardic acid & (Cunha et al., 2017) \\
\hline
\end{tabular}

et al., 2015, Michodjehoun-Mestres et al., 2009, Cunha et al., 2017). Quercetin and myricetin derivatives have been identified by their specific ions at $\mathrm{m} / \mathrm{z} 301$ and 317 corresponding to deprotonated molecules. Taking into account the hexose and rhamnose losses in -162 and -146 , the peaks 6,7 and 8 were identified as myricetin-O-hexoside, myricetin-O-rhamnoside and quercetin-O-rhamnoside, respectively, and the peaks 9, 10 and 11 as myricetin and quercetin derivatives (Michodjehoun-Mestres et al., 2009, Cunha et al., 2017). The fragmentation pattern of peak 12 helped identify the fatty acid trihydroxyoctadecenoic acid through data reported in the literature (Farag et al., 2015). Anacardic acids are commonly identified in Anacardiaceae, and peaks 13, 14 and 15 were identified as anacardic acids 15:3, 15:2 and 15:1 which differ by the absence of double bonds (Michodjehoun-Mestres et al., 2009).

\section{Antimicrobial effect of cashew apple coproduct extracts}

The agar diffusion method is recommended to evaluate antimicrobial susceptibility in vitro, through qualitative results, and is widely used in screening of new agents with antimicrobial potential, such as plant extracts and microorganisms (Balouiri et al., 2016). The CBE-F and CBE-P were tested against strains of Gram-positive (Listeria monocytogenes and Staphylococcus aureus) and
Gram-negative bacteria (Escherichia coli, Salmonella enteritidis and Pseudomonas aeruginosa) by the diffusion method in agar. The results are presented in Table 5 based on the diameter size of the inhibition halos formed. The CBE-P was active only against the strains of Gram-positive bacteria, with inhibition halos larger than $9 \mathrm{~mm}$ (Table 5). The Listeria monocytogenes proved to be more sensitive to the CBE-P, producing an inhibition halo of $17 \mathrm{~mm}$. However, Staphylococcus aureus was also susceptible to the extracts evaluated; reaching the same values of inhibition halo for both extracts (15 mm) (Table 5). Generally, Gram-positive bacteria are more sensitive to the action of antimicrobials from plant extracts (Engels et al., 2011, Rodríguez-Carpena et al., 2011). The higher resistance of Gram-negative cells is attributed mainly to their cell wall structures, which present an outer membrane and a lipopolysaccharide layer acting as a barrier, and these are able to restrict the diffusion of compounds (e.g macromolecules and hydrophobic compounds) into the cells (Raybaudi-Massilia et al., 2009).

Based on the preliminary results of the agar diffusion assays, the bacterial strains sensitive to the extracts tested (inhibition halo $\geq 9 \mathrm{~mm}$ ) were selected for the broth microdilution assay. This method was used to determine the antimicrobial potential of the extracts, and therefore 
it was possible to define the minimum inhibitory (MIC) and minimum bactericidal (MBC) concentrations (Table 6).

The CBE-P showed the best inhibitory potential, with a MIC value of $4.425 \mu \mathrm{g} \mathrm{mL}^{-1}$ for both microorganisms tested (Table 6). For CBE-F, a higher concentration was required to obtain a complete inhibition of the L. monocytogenes and $S$. aureus bacteria, with MIC values of $8.300 \mu \mathrm{g} \mathrm{mL}^{-1}$ (Table 6). Dias-Souza et al. (2017) reported that the extract of pulp cashew presented inhibitory and bactericidal effects against Staphylococcus aureus strains at 15.60 and $125 \mu \mathrm{g} \mathrm{mL}{ }^{-1}$ respectively; and HPLC analysis confirmed the presence of polyphenols associated with antimicrobial activity.

Interestingly, the $\mathrm{MBC}$ found for the CBE-P extracts was $8.850 \mu \mathrm{g} \mathrm{mL}^{-1}$ for both bacterial strains tested; and curiously, CBE-F presented inhibitory and bactericidal action with the same minimum concentration $(8.300 \mu \mathrm{g}$ $\mathrm{mL}^{-1}$ ) (Table 6). Furtado et al. (2000) investigated the antimicrobial activity of the hydroalcoholic extract of cashew apple coproducts against Streptococcus mutans AU 159 and its biofilm and obtained a MIC and MBC of 500 and $1000 \mu \mathrm{g} \mathrm{mL}^{-1}$, respectively.

Table 5: Antimicrobial activity of cashew apple coproduct extracts against bacterial strains by the diffusion method in agar

\begin{tabular}{lccccc}
\hline \multirow{2}{*}{ Extracts } & \multicolumn{5}{c}{ Inhibition halo $(\mathrm{mm}) \mathbf{1}$} \\
\cline { 2 - 6 } & SA & LM & EC & SE & PA \\
\hline CBE-Phenolics & 15 & 17 & 0 & 0 & 0 \\
CBE-Flavonoids & 15 & 12 & 0 & 0 & 0 \\
\hline
\end{tabular}

CBE-Phenolic: phenolic optimized extract from cashew-apple coproduct; CBE-Flavonoid: flavonoid optimized extract from cashew-apple coproduct; SA: Staphylococcus aureus ATCC 27664; LM: Listeria monocytogenes ATCC 19115; EC: Escherichia coli ATCC 25922; SE: Salmonella Enteritidis IAL 1132; PA: Pseudomonas aeruginosa IAL 1026;

'Diameters $\geq 9 \mathrm{~mm}$ were considered positive, indicating bacterial sensitivity to the extracts

Table 6: Minimum inhibitory concentration (MIC) and minimum bacterial concentration (MBC) of cashew-apple coproduct extracts for Listeria monocytogenes and Staphylococcus aureus

\begin{tabular}{|c|c|c|c|c|}
\hline \multirow[t]{3}{*}{ Extracts } & \multicolumn{4}{|c|}{ Bacterial strains } \\
\hline & \multicolumn{2}{|c|}{$\begin{array}{c}\text { Listeria } \\
\text { monocytogenes } \\
\text { (ATCC 19115) }\end{array}$} & \multicolumn{2}{|c|}{$\begin{array}{c}\text { Staphylococcus } \\
\text { aureus } \\
\text { (ATCC 27664) }\end{array}$} \\
\hline & $\mathrm{MIC}^{1}$ & $\mathrm{MBC}^{2}$ & MIC & MBC \\
\hline $\begin{array}{l}\text { CBE-Phenolics } \\
\left(\mu \mathrm{g} \mathrm{mL}^{-1}\right)\end{array}$ & 4.425 & 8.850 & 4.425 & 8.850 \\
\hline $\begin{array}{l}\text { CBE-Flavonoids } \\
\left(\mu \mathrm{g} \mathrm{mL}^{-1}\right)\end{array}$ & 8.300 & 8.300 & 8.300 & 8.300 \\
\hline
\end{tabular}

CBE-Phenolic: phenolic optimized extract from cashew-apple coproduct; CBE-Flavonoid: flavonoid optimized extract from cashew-apple coproduct. ${ }^{1}$ Lowest concentration of extracts that completely inhibited microbial growth (increase of $\leq 0.05$ in the optical density (OD) at $630 \mathrm{~nm}$ after $24 \mathrm{~h}$ of incubation at $35^{\circ} \mathrm{C}$ )

${ }^{2}$ Lowest concentration of extracts that reduced at $3.0 \log _{10} \mathrm{CFU} / \mathrm{mL}(99.99 \%)$ of viable cells after plating of suspension present in inhibitory wells.

\section{CONCLUSION}

In the present study, the influence of ethanol (\%) on the extraction of antioxidant compounds from cashewapple coproduct was significant. The optimized processes configuration for phenolics (ethanol $42.16 \%(v / v)$ and extraction times of $37.34 \mathrm{~min}$ ) and flavonoids (ethanol $37.15 \%(v / v)$ and extraction times of $25.13 \mathrm{~min})$ providing a great yield of $750 \mathrm{mg}$ of gallic acid per $100 \mathrm{~g}^{-1}$ and $479.07 \mathrm{mg}$ of quercetin per $100 \mathrm{~g}^{-1}$, respectively. These results suggested ultrasound-assisted extraction as an alternative method to obtain bioactive compounds from cashew-apple coproduct using less solvent and shorter process time. In addition, the extracts presented antioxidant compounds such as quercetin and myricetin derivatives, gallic acid and anacardic acid, which may have contributed to antimicrobial effect against Staphylococcus aureus and Listeria monocytogenes.

\section{ACKNOWLEDGEMENTS}

The authors are grateful to $\mathrm{CNPq}$ for supported this research.

\section{Authors' contributions}

Amanda Germano Silveira and Mônica Maria de Almeida Lopes collaborated with chemical analysis from extracts. Elaine Cristina Pereira performed the microbiological analysis. George Meredite Cunha de Castro and Thais Andrade Germano performed the statistical analysis. Luciana de Siqueira Oliveira collaborated with chemical analysis from extracts and manuscript writing. Paulo Riceli Vasconcelos Ribeiro and Kirley Marques Canuto performed analysis of the phenolic profile (UPLC-QTOFMS chromatography) and discussed the results obtained. Maria Raquel Alcântara de Miranda and Joelia Marques de Carvalho collaborated in the discussion of the results and manuscript writing.

\section{CONFLICT OF INTEREST}

The authors declared that there is no conflict of interest with respect to research, authorship and/or publication of this article.

\section{REFERENCES}

Arruda, H. S., G. A. Pereira, D. R. Morais, M. N. Eberlin, and G. M. Pastore. 2018. Determination of free, esterified, glycosylated and insoluble-bound phenolics composition in the edible part of araticum fruit (Annona crassiflora Mart.) and its by-products by HPLC-ESI-MS/MS. Food Chem. 245: 738-749.

Assunção, R. B. and A. Z. Mercadante. 2003. Carotenoids and 
ascorbic acid from cashew apple (Anacardium occidentale L.): Variety and geographic effects. Food Chem. 81: 495-502.

Ayala-Zavala, J. F., V. Vega-Vega, C. Rosas-Dominguez, H. PalafoxCarlos, J. A. Villa-Rodriguez, M. W. Siddiqui, J. E. Dávila-Aviña and G. A. González-Aguilar. 2011. Agro-industrial potential of exotic fruit byproducts as a source of food additives. Food Res. Int. 44: 1866-1874.

Bataglion, G. A., F. M. da Silva, M. N. Eberlin and H. H. Koolen. 2015. Determination of the phenolic composition from Brazilian tropical fruits by UHPLC-MS/MS. Food Chem. 180: 280-287.

Branen, J. K. and P. M. Davidson. 2004. Enhancement of nisin, lysozyme, and monolaurin antimicrobial activities by ethylenediaminetetraacetic acid and lactoferrin. Int. J. Food Microbiol. 90: 63-74.

Brandt, A. L., A. Castillo, K. B. Harris, J. T. Keeton, M. D. Hardin and T. M. Taylor. 2010. Inhibition of Listeria monocytogenes by food antimicrobials applied singly and in combination. J. Food Sci. 75: 557-563.

Balouiri, M., M. Sadiki and S. K. Ibnsouda. 2016. Methods for in vitro evaluating antimicrobial activity: A review. J Pharm Anal. 6: 71-79.

Chen, W., W. P. Wang, H. S. Zhang and Q. Huang. 2012. Optimization of ultrasonic-assisted extraction of water-soluble polysaccharides from Boletus edulismycelia using response surface methodology. Carbohydr. Polym. 87: 614-619.

Chen, M., Y. Zhao and S. Yu. 2015. Optimisation of ultrasonic-assisted extraction of phenolic compounds, antioxidants, and anthocyanins from sugar beet molasses. Food Chem. 172: 543-550.

Chemat, F., Z. Huma, and K. M. Khan. 2011. Applications of ultrasound in food technology: Processing, preservation and extraction. Ultrason Sonochem. 18: 813-835.

CLSI. 2012. Performance Standards for Antimicrobial Disk Susceptibility Tests, Approved Standard. $7^{\text {th }}$ ed. CLSI document M02-A11. Clinical and Laboratory Standards Institute, Pennsylvania.

Cunha, A. G., E. S. Brito, C. F. H. Moura, P. R. V. Ribeiro and M. R. A. Miranda. 2017. UPLC-qTOF-MS/MS-based phenolic profile and their biosynthetic enzyme activity used to discriminate between cashew apple (Anacardium occidentale L.) maturation stages. J. Chromatogr. B. 1051: 24-32.

Dias-Souza, M. V., R. M. Santos, E. P. Siqueira and P. H. FerreiraMarçal. 2017. Antibiofilm activity of cashew juice pulp against Staphylococcus aureus, high performance liquid chromatography/diode array detection and gas chromatographymass spectrometry analyses, and interference on antimicrobial drugs. J Food Drug Anal. 25: 589-596.

Engels, C., A. Schieber and M. G. Gänzle. 2011. Inhibitory spectra and modes of antimicrobial action of gallotannins from mango kernels (Mangifera indica L.). Appl. Environ. Microbiol. 77: 2215-2223.

Fan, J. P, J. Cao, X. H. Zhang, J. Z. Huang, T. Kong, S. Tong and J. H. Zhu. 2012. Optimization of ionic liquid based ultrasonic assisted extraction of puerarin from Radix Puerariae Lobatae by response surface methodology. Food Chem. 135: 2299-2306.

Farag, M. A., S. T. Sakna, N. M. El-Fiky, M. M. Shabana and L. A. Wessjohann. 2015. Phytochemical, antioxidant and antidiabetic evaluation of eight Bauhinia L. species from Egypt using UHPLC-PDA-qTOF-MS and chemometrics. Phytochemistry. 119: 41-50.

Fonteles, T. V., A. K. F. Leite, A. R. A. Silva, A. P. G. Carneiro, E. C. Miguel, B. S. Cavada, F. A. N. Fernandes and S. Rodrigues. 2016. Ultrasound processing to enhance drying of cashew apple bagasse puree: Influence on antioxidant properties and in vitro bioaccessibility of bioactive compounds. Ultrason. Sonochem. 31: 237-249.
Furtado, M. A. M., F. C. S. Alves, J. L. Martins, M. A. Vasconcelos, V. S. C. Ramos, G. S. Sousa, R. Pulido, L. Bravo and F. Saura-Calixto. 2000. Antioxidant activity of dietary polyphenols as determined by a modified ferric reducing/antioxidant power assay. J. Agric. Food Chem. 48: 3396-3402.

Hernandez, Y., M. G. Lobo and M. Gonzalez. 2009. Factors affecting sample extraction in the liquid chromatographic determination of organic acids in papaya and pineapple. Food Chem. 114: 734-741.

Leonelli, C. and T. J. Mason. 2010. Microwave and ultrasonic processing: Now a realistic option for industry. Chem. Eng. Process. 49: 885-900.

Li, Q. and C. Fu. 2005. Application of response surface methodology for extraction optimization of germinant pumpkin seeds protein. Food Chem. 92: 701-706.

Ma, Y. Q., J. C. Chen, D. H. Liu and X. Q. Ye. 2009. Simultaneous extraction of phenolic compounds of citrus peel extracts: Effect of ultrasound. Ultrason. Sonochem. 16: 57-62.

Macedo, M., R. D. P. Rodrigues, G. A. S. Pinto and E. S. Brito. 2015. Influence of pectinolytic and cellulosic enzyme complexes on cashew bagasse maceration in order to obtain carotenoids. J. Food Sci. Tech. 52: 3689-3693.

Martins, S., S. I. Mussatto, G. Martínez-Avila, J. Montãnez-Saenz, C. N. Aguilar and J. A. Teixeira. 2011. Bioactive phenolic compounds: production and extraction by solid-state fermentation: A review. Biotechnol. Adv. 29: 365-373.

Michodjehoun-Mestres, L., J. M. Souquet, H. Fulcrand, C. Bouchut, M. Reynes and J. M. Brillouet. 2009. Monomeric phenols of cashew apple (Anacardium occidentale L.). Food Chem. 112: 851-857.

Obanda, M. and P. O. Owuor. 1997. Flavanol composition and caffeine content of green leaf as quality potential indicators of Kenyan black teas. J. Sci. Food Agric. 74: 209-215.

Oliveira, D. A., A. A. Salvador, A. S. Junior, E. F. A. Smânia, M. Maraschin and S. R. S. Ferreira. 2013. Antimicrobial activity and composition profile of grape (Vitis vinifera) pomace extracts obtained by supercritical fluids. J. Biotechnol. 164: 423-432.

Patil, V., S. Angadi and S. Devdhe. 2015. Determination of quercetin by UV spectroscopy as quality control parameter in herbal plant:Cocculus hirsutus. J. Chem. Pharm. Res. 7: 99-104.

Pinho, C., A. Melo, C. Mansilha and I. M. Ferreira. 2011. Optimization of conditions for anthocyanin hydrolysis from red wine using response surface methodology (RSM). J. Agric. Food Chem. 59: 50-55.

Raybaudi-Massilia, R. M., J. Mosqueda-Melgar, R. Soliva-Fortuny and O. Martín-Belloso. 2009. Control of pathogenic and spoilage microorganisms in fresh-cut fruits and fruit juices by traditional and alternative natural antimicrobials. Compr. Rev. Food Sci. 8: 157-180

Rezende, Y. R. R., J. P. Nogueira and N. Narain. 2017. Comparison and optimization of conventional and ultrasound assisted extraction for bioactive compounds and antioxidant activity from agro-industrial acerola (Malpighia emarginata DC) residue. LWT Food Sci. Technol. 85: 158-169.

Rodríguez-Carpena, J. G., D. Morcuende, M. J. Andrade, P. Kylli and M. Estévez. 2011. Avocado (Persea americana Mill.) phenolics, in vitro antioxidant and antimicrobial activities, and inhibition of lipid and protein oxidation in porcine patties. J. Agric. Food Chem. 59: 5625-5635.

Rodrigues, S., F. A. Fernandes, E. S. de Brito, A. D. Sousa and N. Narain. 2015. Ultrasound extraction of phenolics and anthocyanins from Jabuticaba peel. Ind. Crop. Prod. 69: 400-407.

Rodsamran, P. and R. Sothornvit. 2019. Extraction of phenolic 
compounds from lime peel waste using ultrasonic-assisted and microwave-assisted extractions. Food Biosci. 28: 66-73.

Silva, R. A., R. R. Dihl, D. N. Santos, B. R. R. Abreu, A. Lima, H. H. R. Andrade and M. Lehmann. 2013. Evaluation of antioxidant and mutagenic activities of honey-sweetened cashew apple nectar. Food Chem. Toxicol. 62: 61-67.

Sousa, A. D., A. I. V. Maia, T. H. S. Rodrigues, K. M. Canuto, P. R. V. Ribeiro, R. C. A. Pereira, R. F. Vieira and E. S. Brito. 2016. Ultrasound-assisted and pressurized liquid extraction of phenolic compounds from Phyllanthus amarus and its composition evaluation by UPLC-QTOF. Ind. Crop. Prod. 79: 91-103.

Spínola, V., J. Pinto and P. C. Castilho. 2015. Identification and quantification of phenolic compounds of selected fruits from Madeira Island by HPLC-DAD-ESI-MSn and screening for their antioxidant activity. Food Chem. 173: 14-30.

Yan, Y. L, C. H. Yu, J. Chen, X. X. Li, W. Wang and S. Q. Li. 2011. Ultrasonic-assisted extraction optimized by response surface methodology, chemical composition and antioxidant activity of polysaccharides from Tremellames enterica. Carbohydr. Polym. 83: $217-224$.

Zhu, C. and X. Liu. 2013. Optimization of extraction process of crude polysaccharides from pomegranate peel by response surface methodology. Carbohydr. Polym. 92: 1197-1202.

Wang, X., Y. Wu, G. Chen, W. Yue, Q. Liang and Q. Wu. 2013. Optimization of ultra-sound assisted extraction of phenolic compounds from Sparganii rhizoma with response surface methodology. Ultrason. Sonochem. 20: 846-854. 